\title{
The Effect of Blood Glucose Concentration on Postasphyxia Cerebral Hemodynamics in Newborn Lambs
}

\author{
ADAM A. ROSENBERG AND ELIZABETH MURDAUGH \\ Department of Pediatrics, Section of Neonatology, University of Colorado School of Medicine, \\ Denver, Colorado 80262
}

\begin{abstract}
The effect of preasphyxia blood glucose concentration on postasphyxia (PA) cerebral hemodynamics was examined in $\mathbf{2 1}$ newborn lambs. Glucose was unregulated in one group $(n=7)$, and controlled throughout the study by glucose clamp in hyperglycemic $(n=7)$ and hypoglycemic $(n=7)$ groups. Cerebral blood flow, determined using radiolabelled microspheres, and arterial and sagittal sinus $\mathrm{O}_{2}$ contents were measured at control, $5 \mathrm{~min}$, 1,2 , and $4 \mathrm{~h}$ after resuscitation from an asphyxial insult. Preasphyxia blood glucoses were $6.48 \pm 0.55 \mathrm{mM}$ (mean $\pm \mathrm{SEM}$ ), $12.08 \pm 0.80$, and $2.66 \pm 0.14$ in the three study groups. In all three groups, 5 min PA cerebral blood flow was significantly increased from control. In the late period after asphyxia, the unregulated group had decreased cerebral blood flow compared with control, $53.2 \pm 3.8 \mathrm{~mL} \cdot 100$ $\mathrm{g}^{-1} \cdot \min ^{-1}$, mean $\pm \mathrm{SEM}, p<0.01 ; 49.6 \pm 2.0, p<0.005$ $53.4 \pm 3.0, p<0.01$, at 1,2 , and $4 \mathrm{~h} \mathrm{PA}$, respectively, versus $85.7 \pm 6.9$ at control, whereas both the hyper- and hypoglycemic groups did not differ significantly from control measurements. Cerebral oxygen consumption $\left(\mathrm{CMRO}_{2}\right)$ was significantly decreased in all three groups 5 min PA and remained decreased in the late period after asphyxia in both the unregulated and hypoglycemic groups. In the unregulated group, $\mathrm{CMRO}_{2}$ was $191 \pm 14 \mu \mathrm{M} \cdot 100$ $\mathrm{g}^{-1} \cdot \min ^{-1}$, mean $\pm \mathrm{SEM}, p<0.05 ; 200 \pm 4$; and $181 \pm$ $10, p<0.05$ at 1,2 , and $4 \mathrm{~h}$, respectively, PA versus 251 \pm 12 at control. In the hypoglycemic group, $\mathrm{CMRO}_{2}$ was $170 \pm 9 \mu \mathrm{M} \cdot 100 \mathrm{~g}^{-1} \cdot \mathrm{min}^{-1}$, mean $\pm \mathrm{SEM}, p<0.05 ; 174$ $\pm 14, p<0.05 ;$ and $183 \pm 17$ at 1,2 , and $4 \mathrm{~h} \mathrm{PA}$, respectively, versus $231 \pm 15$ at control. $\mathrm{CMRO}_{2}$ did not differ from control in the hyperglycemic group at 1,2 , and $4 \mathrm{~h}$ PA. In our newborn lamb postasphyxia model, $\mathrm{CMRO}_{2}$ was best maintained PA when the lambs were hyperglycemic before asphyxia and throughout the recovery period. To the extent that more rapid recovery of $\mathrm{CMRO}_{2}$ postasphyxia is a favorable outcome, these data may have implications for clinical management. (Pediatr Res 27: 454 459, 1990)
\end{abstract}

\section{Abbreviations}

CBF, cerebral blood flow

$\mathrm{CMRO}_{2}$, cerebral oxygen consumption

PA, postasphyxia

$\mathrm{PaO}_{2}$, arterial $\mathrm{O}_{2}$ tension

$\mathrm{PaCO}_{2}$, arterial $\mathrm{CO}_{2}$ tension

Received October 27, 1989; accepted December 19, 1989

Correspondence and reprints: Adam A. Rosenberg, M.D., University of Colorado Health Sciences Center, 4200 East 9th Avenue, Box B195, Denver, CO 80262. Supported by NIH Grant RO1-HL36301.
Previous studies in a newborn lamb postasphyxia model have demonstrated abnormalities in PA CBF and $\mathrm{CMRO}_{2}$. Immediately after resuscitation from asphyxia, there was a marked increase in CBF. However, despite this overperfusion, $\mathrm{CMRO}_{2}$ was decreased. Thirty min to $4 \mathrm{~h}$ after resuscitation, both $\mathrm{CBF}$ and $\mathrm{CMRO}_{2}$ were decreased (1-3).

One of the variables that may influence the response to perinatal asphyxia is preasphyxia blood glucose concentration. Myers and Yamaguchi (4) found that food-deprived juvenile monkeys recovered with minimal damage after a 10-14 min cardiorespiratory arrest, whereas fed or glucose-pretreated animals developed signs of increased intracranial pressure and died. Considerable data exist in adult ischemia models demonstrating worse neurologic outcome (5), increased pathologic damage and cerebral edema (5-7), impaired cerebral perfusion (8), and poorer recovery of brain energy metabolism $(9,10)$ with glucose administration prior to asphyxia. However, data from newborn rats and mice have demonstrated longer survival in the presence of anoxia/asphyxia with glucose pretreatment, with the most limited survival seen in hypoglycemic animals (11-13). Furthermore, no increase in PA pathologic damage was seen in glucose pretreated animals (12). The role of blood glucose concentration in the response of the developing CNS to asphyxia is clinically relevant to perinatology from the standpoint of whether or not to use i.v. solutions containing glucose during labor of high-risk pregnancies.

Therefore, the newborn lamb PA model was used to further examine the effect of preasphyxia glucose concentration. Three groups of lambs were studied: hyperglycemic, hypoglycemic, and a control group in which blood sugar was not regulated. The hypothesis tested was that preasphyxia glucose concentration would influence previously described abnormalities in postasphyxia $\mathrm{CBF}$ and $\mathrm{CMRO}_{2}$.

\section{MATERIALS AND METHODS}

Surgical procedure. Twenty-one newborn lambs were operated on under pentobarbital anesthesia on d 1-5 of life. Polyvinyl chloride catheters $(0.034$ inner diameter $\times 0.054$ outer diameter; Martech Medical Products, Lansdale, PA) were placed in the left ventricle via an axillary artery, in the brachiocephalic artery via an axillary artery, in the abdominal aorta via a femoral artery, in the inferior vena cava via a femoral vein, and in the posterior sagittal sinus proximal to the confluence of the veins. The sagittal sinus catheter was placed through a 1-inch burr hole in the midline proximal to the lambdoidal sutures. The catheters entering through the animal's extremities were protected in a pouch on the abdomen. The sagittal sinus catheter was cut, pinned, and sutured to the lamb's scalp. The animals were returned to their mothers and allowed a $24-48 \mathrm{~h}$ recovery period before study. At that time, all lambs were standing and feeding normally. Previous 
work has demonstrated that $24-48 \mathrm{~h}$ is an adequate time interval to eliminate any pentobarbital effect on CBF (14).

Physiologic measurements. CBF was measured using the reference organ radiolabeled-microsphere technique as previously described $(1,14-16)$. The reference organ was withdrawn through the brachiocephalic artery catheter into a counting vial by a precalibrated pump $\left(2.47 \mathrm{~mL} \cdot \mathrm{min}^{-1}\right.$; Harvard Apparatus, Dover, MA). After completion of the study, animals were killed with T-61 euthanasia solution (American Hoechst, Summerville, $\mathrm{NJ}$ ), position of the catheters was checked, and brains were removed. Brains were placed in formalin for $1 \mathrm{wk}$ and then divided into regions as previously described (1). Regions examined were brainstem (medulla and pons), right and left cerebellum, midbrain/diencephalon, frontal lobes, temporal lobes, occipital lobes, parietal lobes, hippocampi, and caudate nuclei. The radioactivity in each sample was determined using a 3-channel gamma counter (Tracor Analytic, Des Plaines, IL) and regional blood flows calculated as previously described (14). Whole brain flow was calculated using the sum of the radioactive counts and wt for all regions except brainstem and cerebellum. Adequate central mixing of microspheres using a left ventricle injection site has been confirmed in the newborn lamb (15). All reference blood samples and tissue samples contained $>400$ microspheres (17).

Blood samples for $\mathrm{pH}, \mathrm{PCO}_{2}, \mathrm{PO}_{2}$, and $\mathrm{O}_{2}$ content were withdrawn anaerobically into heparinized Natelson glass pipettes from the brachiocephalic artery and sagittal sinus catheters. $\mathrm{Po}_{2}$, $\mathrm{PCO}_{2}$, and $\mathrm{pH}$ were measured at $39.5^{\circ} \mathrm{C}$ using the radiometer BMS3 MK2 (Radiometer, Copenhagen, Denmark). Blood Hb concentration expressed at $\mathrm{O}_{2}$ capacity and $\mathrm{O}_{2}$ saturation were measured colorimetrically in duplicate by a hemoximeter (Radiometer), and $\mathrm{O}_{2}$ content was calculated as the product of $\mathrm{Hb}$ and $\mathrm{O}_{2}$ saturation. Blood glucose measurements were made using a Yellow Springs glucose analyzer (Yellow Springs Instrument Co., Yellow Springs, $\mathrm{OH}$ ). Blood pressure (referenced to the right atrium) and heart rate were continuously monitored in the abdominal aorta (Gould Instruments, Oxford, CA).

Experimental procedure. Three groups $(n=7)$ were studied. In the first group (unregulated glucose), no effort was made to control glucose concentration. The animals were taken from the mother just before the study and received neither glucose nor insulin infusions before or during the study. The hyperglycemic group received a bolus of glucose $\left(30 \mathrm{mM} \cdot \mathrm{kg}^{-1}\right)$ followed by a continuous infusion $\left(0.66 \mathrm{mM} \cdot \mathrm{kg}^{-1} \cdot \mathrm{min}^{-1}\right)$ for $2 \mathrm{~h}$ before the study and as needed during the study to maintain a blood glucose $\geq 11.1 \mathrm{mM}$. The hypoglycemic group was fasted for $8 \mathrm{~h}$ before the study. Blood glucose was then decreased with a bolus of insulin $\left(13.5 \mathrm{mU} \cdot \mathrm{kg}^{-1}\right)$ followed by an insulin infusion $(1 \mathrm{mU}$. $\mathrm{kg}^{-1} \cdot \mathrm{min}^{-1}$ ) to maintain a blood glucose $\leq 2.77 \mathrm{mM}$ for $2 \mathrm{~h}$ before and during the study. An infusion of glucose was maintained as needed. Frequent (every 10-15 min) determinations of blood glucose were performed to allow adjustment of infusions to maintain the desired glucose concentration in the hyper- and hypoglycemic groups $(18,19)$. The animals were anesthetized with fentanyl $\left(20 \mu \mathrm{g} \cdot \mathrm{kg}^{-1}\right.$ loading dose followed by $10 \mu \mathrm{g} \cdot \mathrm{kg}^{-1}$. $\mathrm{h}^{-1}$ infusion), paralyzed with pancuronium $\left(0.1 \mathrm{mg} \cdot \mathrm{kg}^{-1}\right)$, intubated, and ventilated with an infant ventilator (Bird Co., Palm Springs, CA) with a baseline gas mixture of $30-35 \% \mathrm{O}_{2}$ and $65-$ $70 \% \mathrm{~N}_{2}$ to provide a $\mathrm{PaO}_{2}$ of $10.7-16.0 \mathrm{kPa}$, and a baseline ventilator rate of $25-35$ breaths $/$ min to provide $\mathrm{PaCO}_{2}$ of $4.4-$ $5.1 \mathrm{kPa}$. Pancuronium and fentanyl have been shown at the doses used in our study to have no effect on $\mathrm{CBF}$ and $\mathrm{CMRO}_{2}$ $(2,20)$.

Measurements of CBF (radiolabeled microspheres), arterial and venous blood gases, and $\mathrm{O}_{2}$ contents were made during the control period. The animals were then subjected to a gradual asphyxial insult by altering inspired gas concentrations and ventilator rate as previously described (1-3). In a stepwise fashion over $30 \mathrm{~min}, \mathrm{PaO}_{2}$ was decreased to $2-2.66 \mathrm{kPa}$, arterial oxygen content was decreased to $0.67-1.12 \mathrm{mM}$, and $\mathrm{PaCO}_{2}$ was in- creased to 8-9.33 $\mathrm{kPa}$. Over the first $60 \mathrm{~min}$ of asphyxia, heart rate and blood pressure were stable, but during the final 10-15 $\mathrm{min}$, the lambs become bradycardic (heart rate $<100$ beats $/ \mathrm{min}$ ) and hypotensive (mean arterial blood pressure, $20-35 \mathrm{~mm} \mathrm{Hg}$ ). The lambs were then returned to baseline ventilator settings and fractional inspired oxygen concentration. CBF (microspheres) arterial and venous blood gases, and $\mathrm{O}_{2}$ contents were measured at $5 \mathrm{~min}, 1,2$, and $4 \mathrm{~h}$ after the termination of the insult. After the $4 \mathrm{~h}$ measurement, the animals were killed. Care and handling of animals were in accord with the published guidelines of the National Institutes of Health and has been approved by the Animal Care Committee of the University of Colorado.

Data analysis. $\mathrm{CMRO}_{2}$ and fractional $\mathrm{O}_{2}$ extraction were calculated as previously described $(14,21)$. Comparisons were made for cerebral hemodynamic and other physiologic variables among control and the four postasphyxia determinations within each of the three experimental groups using analysis of variance with a repeated measures design. Postanalysis of variance comparisons were performed using $t$ tests with a Bonferroni correction for multiple comparisons. Regional flow data from the right and left sides of the brain were combined before analysis because no left-right differences were seen. Significance compared to control was determined at the $p<0.05$ level. $\mathrm{CBF}, \mathrm{CMRO}_{2}$, and fractional $\mathrm{O}_{2}$ extraction data are also presented as percent of control measurements for the three groups.

\section{RESULTS}

Blood glucose concentrations during the course of the study are presented for the three study groups in Figure 1. In the unregulated group, glucose concentration was significantly increased from the control at $5 \mathrm{~min}$ PA. In the hypoglycemic group, glucose did not differ from control at anytime, whereas

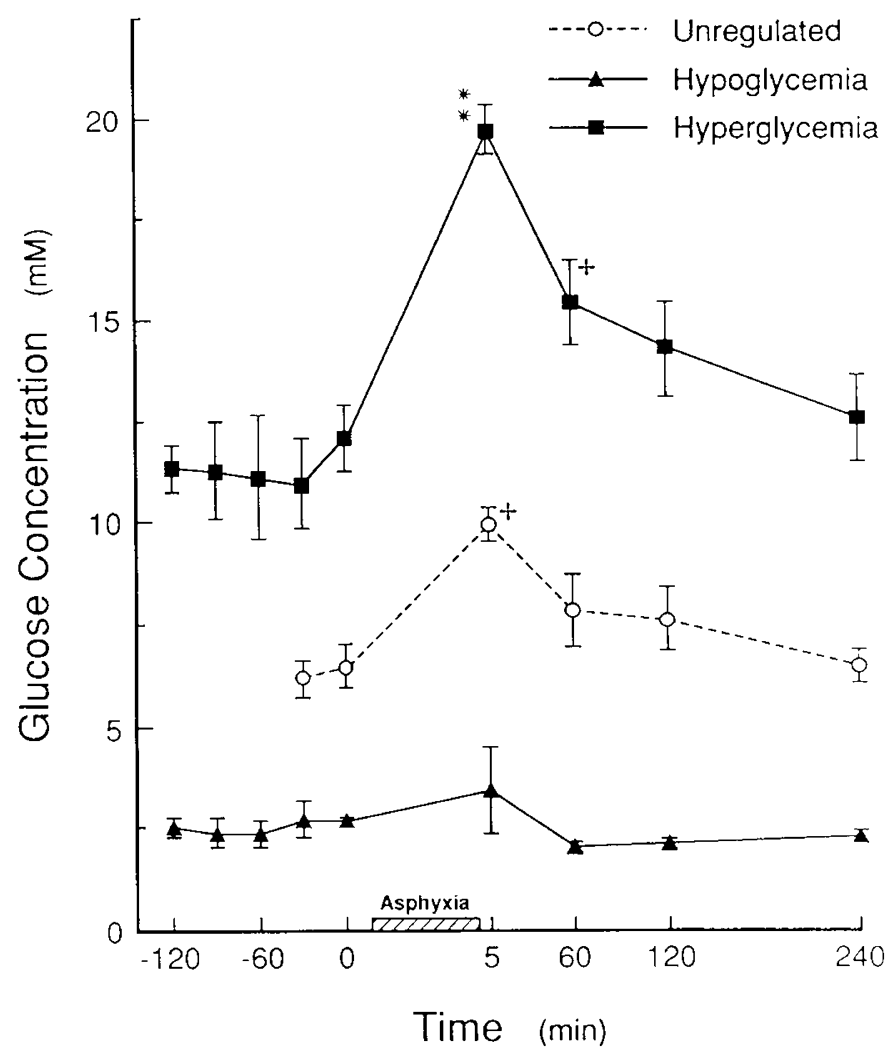

Fig. 1. Blood glucose concentration (mM) over time in the unregulated glucose, hyperglycemic, and hypoglycemic groups. Zero (0) time represents the control measurement that is followed by the $75-\mathrm{min}$ period of asphyxia. Measurements were then made at $5 \mathrm{~min}, 1,2$, and $4 \mathrm{~h}$ PA. Values are mean \pm SEM. $+p<0.01$ compared to control; ${ }^{* *} p<0.001$ compared to control. 
in the hyperglycemic group, glucose concentration was significantly greater than control at $5 \mathrm{~min}$ and $1 \mathrm{~h}$ PA.

$\mathrm{CBF}$ for the unregulated glucose, hyperglycemic, and hypoglycemic groups are presented in Figure 2. Control CBF did not differ among the three groups and was $85.7 \pm 6.9,80.3 \pm 9.2$, and $76.2 \pm 2.4 \mathrm{~mL} \cdot 100 \mathrm{~g}^{-1} \cdot \mathrm{min}^{-1}$ in the unregulated, hyperglycemic, and hypoglycemic groups, respectively. Five min after resuscitation from asphyxia, $\mathrm{CBF}$ was significantly increased in all three groups. Cerebral hypoperfusion was seen in the unregulated glucose group at 1,2, and $4 \mathrm{~h} \mathrm{PA}$, but was absent in the hypo- and hyperglycemic groups. Regional brain blood flows (Figs. 3-5) demonstrated changes similar to those seen with whole brain flow. No differences were present among the three study groups in physiologic variables $\left(\mathrm{PaO}_{2}\right.$, arterial oxygen content, $\mathrm{PaCO}_{2}$, mean arterial blood pressure) known to affect postasphyxia CBF (Table 1).

Changes in postasphyxia $\mathrm{CMRO}_{2}$ are presented in Figure 6. Control $\mathrm{CMRO}_{2}$ did not differ among the three groups and was $251 \pm 12,222 \pm 14$, and $231 \pm 15 \mu \mathrm{M} \cdot 100 \mathrm{~g}^{-1} \cdot \mathrm{min}^{-1}$ in the unregulated, hyperglycemic, and hypoglycemic groups, respectively. In all three study groups, $\mathrm{CMRO}_{2}$ was significantly decreased from control $5 \mathrm{~min}$ PA. In the hyperglycemic group, $\mathrm{CMRO}_{2}$ returned to control levels at 1,2 , and $4 \mathrm{~h} \mathrm{PA}$. In the hypoglycemic group, $\mathrm{CMRO}_{2}$ remained significantly below control at 1 and $2 \mathrm{~h} \mathrm{PA}$, whereas significant decreases compared to control were present at 1 and $4 \mathrm{~h}$ PA in the unregulated glucose group. In the unregulated glucose group, the late decrease in $\mathrm{CMRO}_{2}$ was associated with a significant decrease in CBF and no change in fractional $\mathrm{O}_{2}$ extraction compared with control (Fig. 7). In the hypoglycemic group, $\mathrm{CBF}$ was equal to or greater than control. Thus, the decrease in $\mathrm{CMRO}_{2}$ was related to a decrease in fractional $\mathrm{O}_{2}$ extraction (Fig. 7).

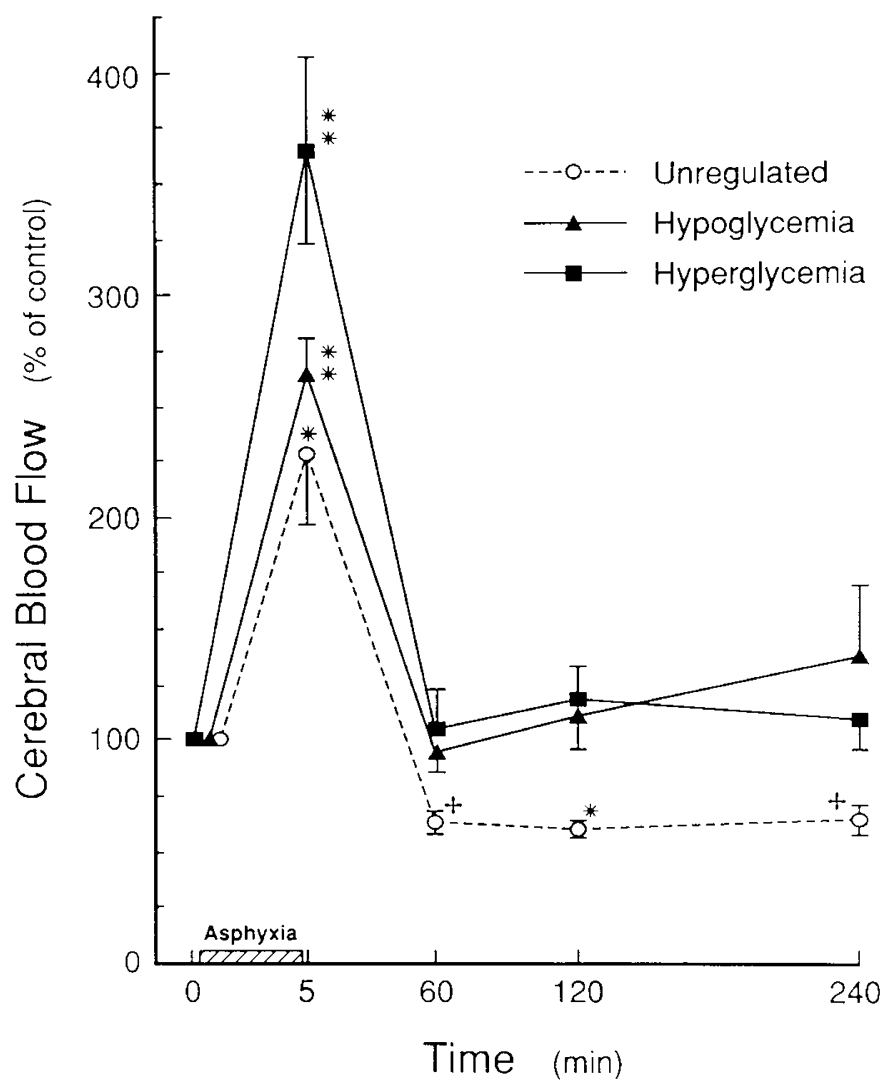

Fig. 2. CBF (\% of control) over time in the unregulated glucose, hyperglycemic, and hypoglycemic groups. Zero $(0)$ time represents the control measurement that is followed by the 75 -min period of asphyxia. Measurements were then made at $5 \mathrm{~min}, 1,2$, and $4 \mathrm{~h} \mathrm{PA}$. Values are mean \pm SEM. $+p<0.01$ compared to control, ${ }^{*} p<0.005$ compared to control, ${ }^{* *} p<0.001$ compared to control.

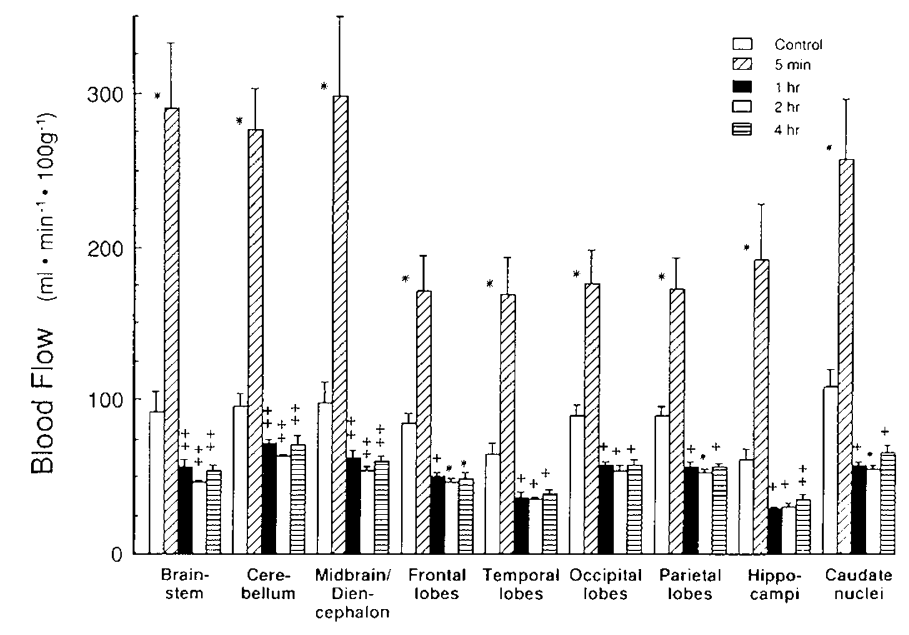

Fig. 3. Regional brain blood flows $\left(\mathrm{mL} \cdot 100 \mathrm{~g}^{-1} \cdot \mathrm{min}^{-1}\right)$ at control, 5 $\min , 1,2$, and $4 \mathrm{~h} \mathrm{PA}$ for the unregulated glucose group. All values are mean \pm SEM. $++p<0.05$ compared to control $+p<0.01$ compared to control, ${ }^{*} p<0.005$ compared to control.

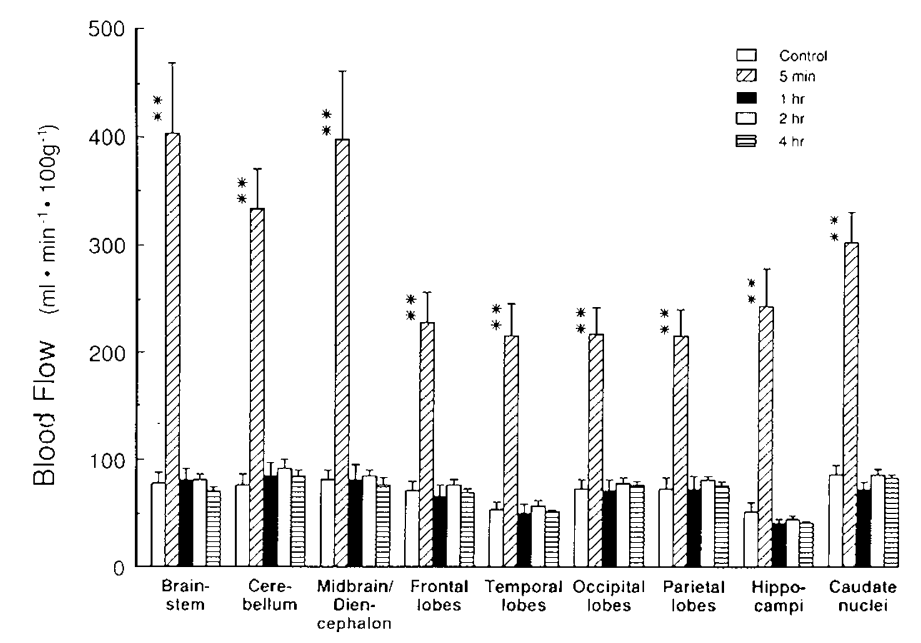

Fig. 4. Regional brain blood flows $\left(\mathrm{mL} \cdot 100 \mathrm{~g}^{-1} \cdot \mathrm{min}^{-1}\right)$ at control, 5 $\min , 1,2$, and $4 \mathrm{~h}$ PA for the hyperglycemic group. All values are mean \pm SEM. ${ }^{* *} p<0.001$ compared to control.

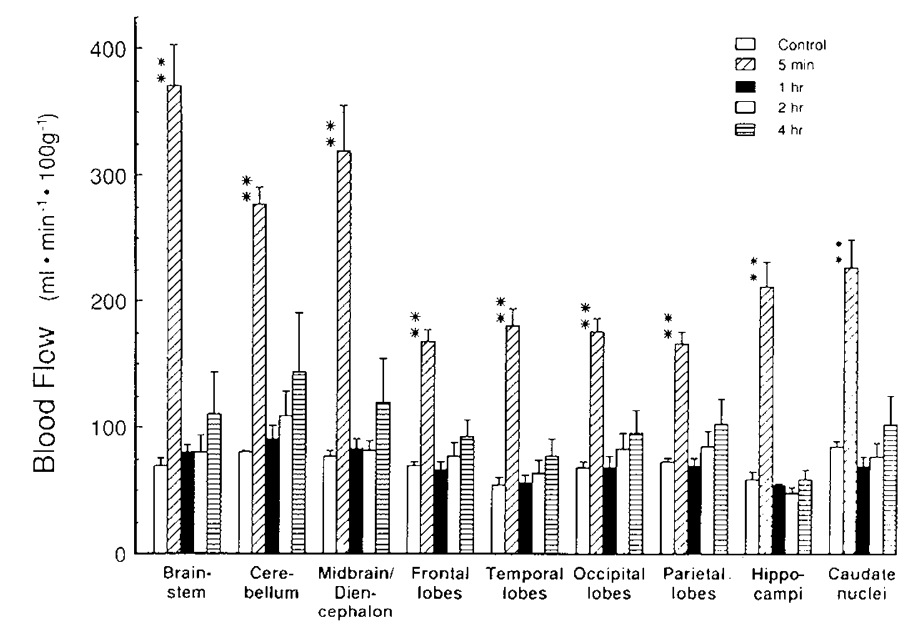

Fig. 5. Regional brain blood flows $\left(\mathrm{mL} \cdot 100 \mathrm{~g}^{-1} \cdot \mathrm{min}^{-1}\right)$ at control, 5 min, 1, 2, and $4 \mathrm{~h} \mathrm{PA}$ for the hypoglycemic group. All values are mean \pm SEM. ${ }^{* *} p<0.001$ compared to control. 
Table 1. Physiologic variables*

\begin{tabular}{|c|c|c|c|c|c|}
\hline & Control & $5 \mathrm{~min} P A$ & $1 \mathrm{~h} \mathrm{PA}$ & $2 \mathrm{hPA}$ & $4 \mathrm{~h}$ PA \\
\hline \multicolumn{6}{|l|}{$\mathrm{PaO}_{2}(\mathrm{kPa})$} \\
\hline Unregulated & $15.4 \pm 0.9$ & $21.9 \pm 1.2 \ddagger$ & $15.1 \pm 0.8$ & $14.7 \pm 0.7$ & $14.6 \pm 0.6$ \\
\hline Hypoglycemia & $16.6 \pm 0.7$ & $23.3 \pm 1.5 \ddagger$ & $17.2 \pm 1.4$ & $14.8 \pm 0.7$ & $15.8 \pm 0.8$ \\
\hline Hyperglycemia & $15.0 \pm 0.8$ & $21.7 \pm 2.5 \ddagger$ & $14.6 \pm 0.8$ & $14.2 \pm 1.0$ & $14.8 \pm 0.5$ \\
\hline \multicolumn{6}{|l|}{$\mathrm{PaCO}_{2}(\mathrm{kPa})$} \\
\hline Unregulated & $4.46 \pm 0.12$ & $3.88 \pm 0.16$ & $4.20 \pm 0.15$ & $4.47 \pm 0.16$ & $4.44 \pm 0.16$ \\
\hline Hypoglycemia & $4.13 \pm 0.09$ & $4.40 \pm 0.17$ & $4.45 \pm 0.21$ & $4.55 \pm 0.24$ & $4.19 \pm 0.11$ \\
\hline Hyperglycemia & $4.57 \pm 0.24$ & $4.35 \pm 0.25$ & $4.41 \pm 0.28$ & $4.65 \pm 0.21$ & $4.52 \pm 0.08$ \\
\hline \multicolumn{6}{|l|}{$\mathrm{pH}$} \\
\hline Unregulated & $7.42 \pm 0.02$ & $6.95 \pm 0.03 \ddagger$ & $7.14 \pm 0.05 \dagger$ & $7.24 \pm 0.05 \dagger$ & $7.35 \pm 0.03$ \\
\hline Hypoglycemia & $7.40 \pm 0.02$ & $6.91 \pm 0.02 \ddagger$ & $7.14 \pm 0.03 \dagger$ & $7.27 \pm 0.03 \dagger$ & $7.28 \pm 0.03 \dagger$ \\
\hline Hyperglycemia & $7.40 \pm 0.02$ & $6.95 \pm 0.04 \ddagger$ & $7.20 \pm 0.05 \dagger$ & $7.30 \pm 0.04$ & $7.35 \pm 0.03$ \\
\hline \multicolumn{6}{|l|}{$\mathrm{CaO}_{2}(\mathrm{mM})$} \\
\hline Unregulated & $6.79 \pm 0.67$ & $7.26 \pm 0.77$ & $7.08 \pm 0.59$ & $7.31 \pm 0.48$ & $6.89 \pm 0.53$ \\
\hline Hypoglycemia & $7.54 \pm 0.36$ & $7.63 \pm 0.40$ & $7.54 \pm 0.49$ & $7.28 \pm 0.45$ & $6.83 \pm 0.45$ \\
\hline Hyperglycemia & $7.41 \pm 0.58$ & $7.46 \pm 0.54$ & $7.54 \pm 0.54$ & $7.50 \pm 0.54$ & $7.28 \pm 0.54$ \\
\hline \multicolumn{6}{|l|}{$\operatorname{MAP}(\mathrm{kPa})$} \\
\hline Unregulated & $11.1 \pm 0.9$ & $13.1 \pm 0.7$ & $11.5 \pm 0.4$ & $11.1 \pm 0.5$ & $10.1 \pm 0.3$ \\
\hline Hypoglycemia & $11.3 \pm 0.7$ & $12.4 \pm 0.8$ & $12.0 \pm 0.9$ & $11.2 \pm 0.8$ & $11.1 \pm 0.9$ \\
\hline Hyperglycemia & $11.5 \pm 0.5$ & $12.5 \pm 0.8$ & $10.9 \pm 0.5$ & $10.5 \pm 0.7$ & $10.1 \pm 0.7$ \\
\hline
\end{tabular}

* All values are mean $\pm \mathrm{SEM} . \mathrm{CaO}_{2}$, arterial $\mathrm{O}_{2}$ content; MAP, mean arterial blood pressure. $1 \mathrm{~mm} \mathrm{Hg}=0.1333 \mathrm{kPa}$. $\dagger p<0.05$.

$\$ p<0.01$.

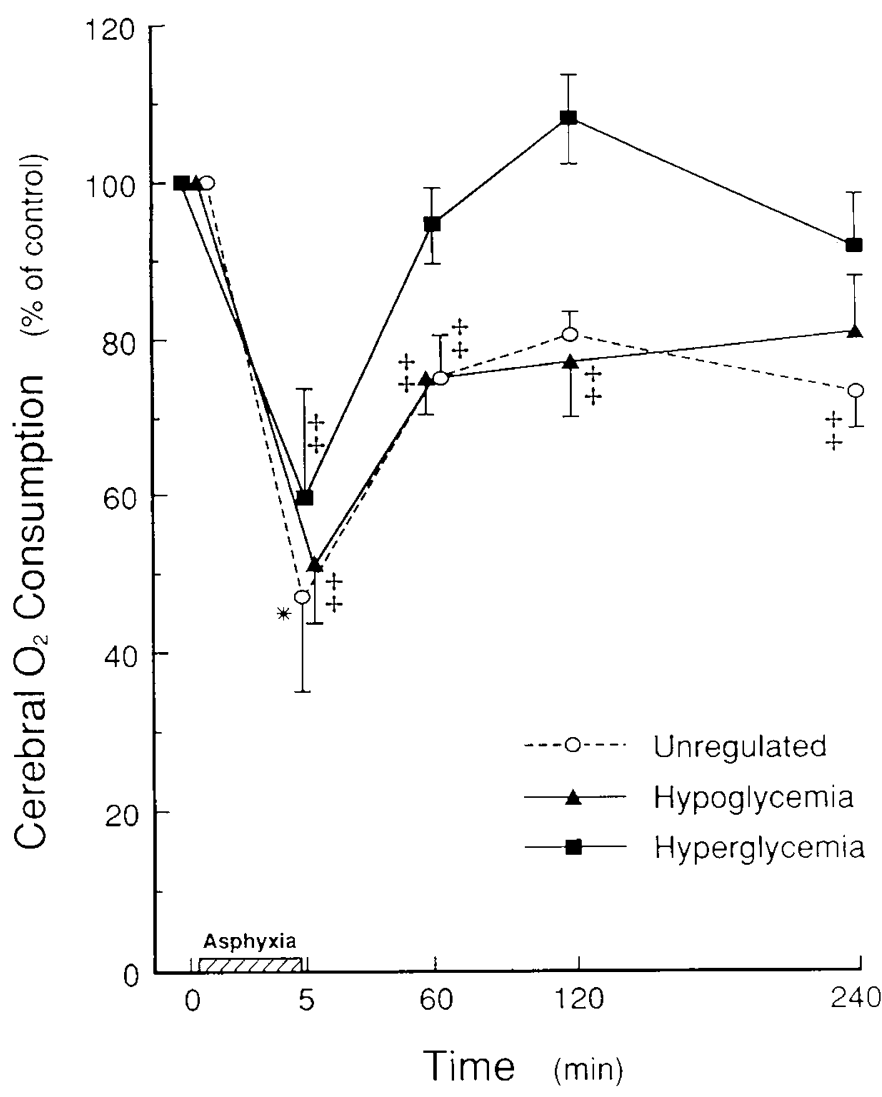

Fig. 6. $\mathrm{CMRO}_{2}$ (\% of control) over time in the unregulated glucose, hyperglycemic, and hypoglycemic groups. Zero (0) time represents the control measurement that is followed by the 75 -min period of asphyxia. Measurements were then made at $5 \mathrm{~min}, 1,2$, and $4 \mathrm{~h}$ PA. All values are mean \pm SEM. $++p<0.05$ compared to control, ${ }^{*} p<0.005$ compared to control.

\section{DISCUSSION}

The role of glucose in postasphyxia/ischemia CBF, cerebral metabolism, and brain injury has been extensively studied, particularly in adult models. The majority of this work suggests that elevated blood glucose is deleterious. Increased blood glucose levels have been associated with worse neurologic outcome (45), increased pathologic damage and cerebral edema (5-7), impaired cerebral perfusion (8), and poorer recovery of brain energy metabolism $(9,10)$. The proposed mechanism for the deleterious effect of increased glucose is excessive production of lactic acid by anaerobic metabolism during asphyxia/ischemia (10, 22-26). The mechanism by which lactic acidosis enhances tissue injury and influences postischemic metabolism and blood flow is not clear. Speculation includes inhibition of oxidative enzymes by lactic acid (25) and increased production of oxygen-free radicals by acidosis-induced enhancement of ferrous iron release (22).

In contrast to the above information, the current investigation suggests a beneficial effect of pretreatment with glucose in the newborn lamb PA model. However, this finding does agree with other data available from studies in immature animals. Newborn rats and mice demonstrate longer survival in the presence of anoxia/asphyxia with glucose pretreatment, with the most limited survival seen in hypoglycemic animals (11-13). Furthermore, PA pathologic damage is not increased in glucose pretreated animals (12). This paradoxical response in the newborn has been examined by Vannucci et al. (27) in greater detail using a model of unilateral carotid artery ligation with superimposed hypoxia in newborn rats in which animals were pretreated with either $50 \%$ glucose or saline solutions. In the glucose pretreated group, brain glucose was maintained at a higher level than in the saline-treated animals through the first 60-90 min of hypoxia in the hemisphere ipsilateral to carotid artery ligation. Brain lactate increased to a similar extent in glucose- and saline-treated animals, and although not statistically significant, adenine nucleotides tended to be better maintained in glucose-treated animals. Glucose use did not differ between the two groups. These findings support the concept that increased cerebral glucose delivery to the immature brain does not result in increased cerebral glucose 


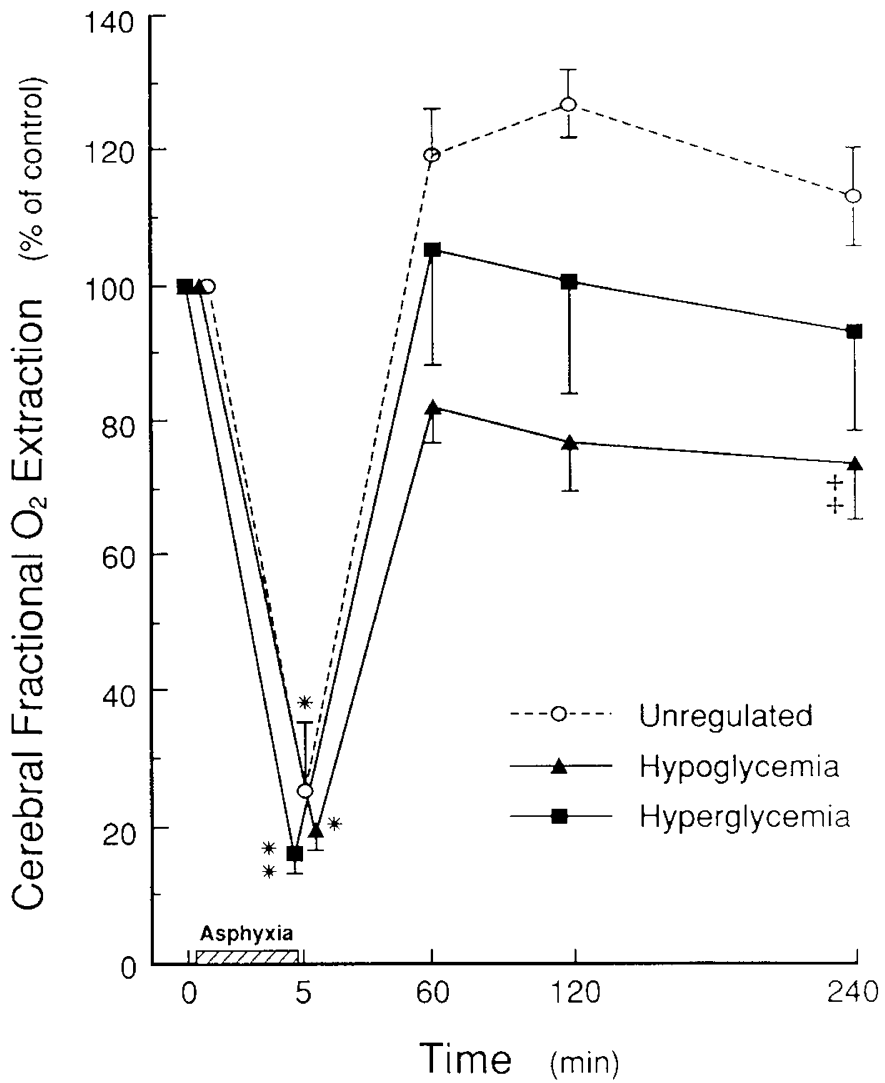

Fig. 7. Cerebral fractional $\mathrm{O}_{2}$ extraction (\% of control) over time in the unregulated glucose, hyperglycemic, and hypoglycemic groups. Zero (0) time represents the control measurement that is followed by the $75-$ min period of asphyxia. Measurements were then made at $5 \mathrm{~min}, 1,2$, and $4 \mathrm{~h}$ PA. All values are mean \pm SEM. $++p<0.05$ compared to control; $* p<0.005$ compared to control, ${ }^{* *} p<0.001$ compared to control.

use and lactate production. Thus, elevated blood glucose concentration is not detrimental in the newborn due to limited entry into and metabolism by the brain. This finding is likely related to low blood-brain barrier transport of glucose (28) and low activity of hexokinase (29).

Although developmental differences may explain variable responses to preasphyxial glucose concentration, the issue cannot be settled that easily. Discrepant data exist in both adult and newborn models. As examples, Ibayashi et al. (30), using an acute incomplete ischemia model in spontaneously hypertensive rats, found hyperglycemia was not detrimental to postischemia $\mathrm{CBF}$ and recovery of ATP levels, whereas studies by Zasslow et al. (31) found that cats exposed to focal ischemia had smaller infarcts in a hyperglycemic group than in control animals. In contrast, Blomstrand et al. (32) demonstrated rapid development of acidosis and reduction of $\mathrm{CMRO}_{2}$, along with a deterioration in neurophysiologic characteristics, during asphyxia in hyperglycemic fetal sheep. It must be noted, however, that the design of their study was very different from our investigation and some of the other studies in immature animals (11-13). Nevertheless, in certain adult models, elevated preasphyxia/ischemia glucose concentration has not been detrimental, whereas it has been associated with negative consequences in at least one perinatal model. Along with developmental differences, species, type of protocol, and type of ischemia (complete versus incomplete, global versus focal) may also influence the response to varying blood glucose concentrations.

Hyperglycemia was associated with a return of CBF, $\mathrm{CMRO}_{2}$, and fractional $\mathrm{O}_{2}$ extraction to control levels during the late period after asphyxia. Neither hyperglycemia (33) nor hyperinsulinemia (34) per se have been shown to increase CBF. Thus, consideration of improved PA perfusion in the hyperglycemic group must evaluate the mechanism of the late hypoperfusion seen in the unregulated glucose group. One possible explanation is cerebral edema impinging on capillaries, thus impairing blood flow (35). Inducing hyperglycemia by increasing serum osmolality might serve to ameliorate cerebral edema and thereby improve cerebral perfusion. However, previous work in the newborn lamb has failed to demonstrate cerebral edema during the period of late hypoperfusion (2). Alternatively, previous work in the newborn lamb has suggested a role for oxygen-free radicalmediated vascular injury in late PA hypoperfusion (3). We can only speculate as to whether the hyperglycemic state may, in some way, influence production of oxygen-free radicals or protect against oxygen-free radical-mediated injury. This speculation must be tempered by the fact that hyperglycemia potentially enhances production of oxygen-free radicals by increasing ferrous iron release (22).

The rapid return of $\mathrm{CMRO}_{2}$ to control levels in the hyperglycemic group could be the result of better mitochondrial performance. However, previous work in the newborn lamb PA model has shown that mitochondrial function in animals in which glucose was not regulated did not differ significantly from control $2 \mathrm{~h}$ PA (36). It should be noted, however, that on average, mitochondrial state 3 respiration, although not significantly different from control, was $70 \%$ of control levels. This is precisely the decrease in $\mathrm{CMRO}_{2}$ that was demonstrated in vivo in the unregulated glucose group in our investigation. This issue merits future evaluation of mitochondrial function PA with variable preasphyxia glucose concentrations. Alternatively, the improved $\mathrm{CMRO}_{2}$ may simply be the result of improved $\mathrm{O}_{2}$ delivery. This concept is supported by our data. At 1, 2, and $4 \mathrm{~h} \mathrm{PA}$, the cerebral fractional $\mathrm{O}_{2}$ extraction, which describes the relationship between $\mathrm{CMRO}_{2}$ and cerebral $\mathrm{O}_{2}$ delivery, is normal.

Hypoglycemia, in contrast to hyperglycemia, led to late PA decrease in $\mathrm{CMRO}_{2}$ despite cerebral perfusion at or above control levels. Hypoglycemia per se has been shown to increase $\mathrm{CBF}$, thus providing an explanation for the return of $\mathrm{CBF}$ to control levels (37). $\mathrm{CMRO}_{2}$ likely remains depressed due to a limitation of metabolizable substrate. This conclusion is supported by the observed decrease in fractional extraction of oxygen by the brain.

A few other issues need to be addressed concerning our study. The first is that microsphere measurement of CBF precluded a determination of brain lactate. Therefore, inferences about the role of lactate or lack thereof in PA abnormalities of CBF and $\mathrm{CMRO}_{2}$ cannot be made from our investigation. Second, the newborn lamb PA model has, to date, assessed only physiologic and biochemical parameters PA. The relationship of abnormalities in $\mathrm{CBF}, \mathrm{CMRO}_{2}$, and mitochondrial function have not been related to pathologic brain injury. With that in mind, although we speculate that improved $\mathrm{CMRO}_{2}$ seen in the hyperglycemic animals is good, this has not been proven to be the case and awaits further studies.

Our data demonstrate improved $\mathrm{CBF}$ and $\mathrm{CMRO}_{2}$ after asphyxia in the hyperglycemic newborn lamb. To the extent that improved $\mathrm{CBF}$ and $\mathrm{CMRO}_{2}$ during this late period after asphyxia is beneficial, these results may have implications for the management of the high-risk pregnancy and the asphyxiated newborn. The exact mechanism of the role of preasphyxia glucose concentration in postasphyxia $\mathrm{CBF}$ and $\mathrm{CMRO}_{2}$ regulation remains to be determined.

Acknowledgments. The authors thank Karin Mote, Karen Trembler, I-da Fan, Y-Ching Fan Cheng, and Lee Hatten for technical assistance, Nancy Briggs for preparation of the manuscript, and William Hay Jr., M.D. and Jane DiGiacomo, M.D. for aid in performing glucose clamp methodology.

\section{REFERENCES}

1. Rosenberg AA 1986 Cerebral blood flow and $\mathrm{O}_{2}$ metabolism after asphyxia in neonatal lambs. Pediatr Res 20:778-782 
2. Rosenberg AA 1988 Regulation of cerebral blood flow after asphyxia in neonatal lambs. Stroke 19:239-244

3. Rosenberg AA, Murdaugh E, White CW 1989 The role of oxygen free radicals in post-asphyxia cerebral hypoperfusion in newborn lambs. Pediatr Res 26:215-219

4. Myers RE, Yamaguchi S 1977 Nervous system effects of cardiac arrest in monkeys. Arch Neurol 34:65-74

5. Pulsinelli WA, Waldman S, Rawlinson D, Plum F 1982 Moderate hyperglycemia augments ischemic brain damage: a neuropathologic study in the rat. Neurology 32:1239-1246

6. Kalimo H, Rehncrona S, Soderfeldt B, Olsson Y, Siesjo BK 1981 Brain lactic acidosis and ischemic cell damage: 2. Histopathology. J Cereb Blood Flow Metab 1:313-327

7. Paljarvi L 1984 Brain lactic acidosis and ischemic cell damage: a topographic study with high-resolution light microscopy of early recovery in a rat model of severe incomplete ischemia. Acta Neuropathol 64:89-98

8. Ginsberg MD, Welsh FA, Budd WW 1980 Deleterious effect of glucose pretreatment on recovery from diffuse cerebral ischemia in the cat. I. Local cerebral blood flow and glucose utilization. Stroke 11:347-354

9. Welsh FA, Sims RE, McKee AE 1983 Effect of glucose on recovery of energy metabolism following hypoxia-oligemia in mouse brain: dose dependence and carbohydrate specificity. J Cereb Blood Flow Metab 3:486-492

10. Welsh FA, Ginsberg MD, Reider W, Budd WW 1980 Deleterious effect of glucose pre-treatment on recovery from diffuse cerebral ischemia in the cat. II. Regional metabolite levels. Stroke 11:355-363

11. Thurston JH Hauhart RE, Jones EM 1974 Anoxia in mice: reduced glucose in brain with normal or elevated glucose in plasma and increased survival after glucose treatment. Pediatr Res 8:238-243

12. Voorhies TE, Rawlinson D, Vannucci RC 1986 Glucose and perinatal hypoxicischemic brain damage. Neurology $36: 1115-1118$

13. Vannucci RC, Vannucci SJ 1978 Cerebral carbohydrate metabolism during hypoglycemia and anoxia in newborn rats. Ann Neurol 4:73-79

14. Rosenberg AA, Jones MD, Traystman RJ, Simmons MA, Molteni RA 1982 Response of cerebral blood flow to changes in $\mathrm{PCO}_{2}$ in fetal, newborn and adult sheep. Am J Physiol 242:H862-H866

15. Rosenberg AA, Jones MD, Koehler RC, Traystman RJ, Lister G 1983 Precautions for measuring blood flow during anemia with the microsphere technique. Am J Physiol 244:H308-H311

16. Heymann MA, Payne BD, Hoffman JIE, Rudolph AM 1977 Blood flow measurements with radionuclide-labelled particles. Prog Cardiovasc Dis 20:55-79

17. Buckberg GD, Luck JL, Payne B, Hoffman JIE, Archie J, Fixler DE 1971 Some sources of error in measuring regional blood flow with radioactive microspheres. J Appl Physiol 31:598-604

18. DeFronzo RA, Tobin JD, Andres R 1979 Glucose clamp technique: a method for quantifying insulin secretion and resistance. Am J Physiol 237:E214E223

19. Hay Jr WW, Meznarich HK, Sparks JW, Battaglia FC, Meschia G 1985 Effect of insulin on glucose uptake in near-term fetal lambs. Proc Soc Exp Biol Med 178:557-564

20. Belik J, Wagerle LC, Delivoria-Papadopoulos M 1984 Cerebral blood flow and metabolism following pancuronium bromide in newborn lambs. Pediatr Res 18:1305-1308

25. Jones MD Traystman RJ, Simmons MA, Molteni RA 1981 The effects of changes in arterial $\mathrm{O}_{2}$ content in cerebral blood flow in the lamb. Am J Physiol 240:H209-H215

22. Pulsinelli WA, Kraig RP, Plum F 1984 Hyperglycemia, cerebral acidosis, and ischemic brain damage. In: Plum F, Pulsinelli WA (eds) Cerebrovascular Diseases 4th ed, Raven Press, New York pp 201-205

23. Myers RE 1979 A unitary theory of causation of anoxic and hypoxic brain pathology. In: Fahn S, Davis IN, Rowland LP (eds) Advances in Neurology, Vol 26. Raven Press, New York pp 195-213

24. Siemkowicz E 1985 The effect of glucose upon restitution after transient cerebral ischemia: a summary. Acta Neurol Scand 71:417-427

25. Siemkowicz E, Gjedde R 1980 Post-ischemic coma in rat: effect of different pre-ischemia blood glucose levels in cerebral metabolic recovery after ischemia. Acta Physiol Scand 1 10:225-232

26. Rehncrona S, Rosen I, Smith ML 1985 Effect of different degrees of brain ischemia and tissue lactic acidosis on the short term recovery of neurophysiologic and metabolic variables. Exp Neurol 87:458-473

27. Vannucci RC, Vasta F, Vannucci SJ 1987 Cerebral metabolic responses of hyperglycemic immature rats to hypoxia-ischemia. Pediatr Res 21:524-529

28. Cremer JE, Cunningham VJ, Pardridge WM 1979 Kinetics of blood-brain barrier transport of pyruvate, lactate and glucose in suckling, weaning and adult rats. J Neurochem 33:439-445

29. Booth RF, Patel TB, Clark JM 1980 The development of enzymes of energy metabolism in the brain of a precocial (guinea pig) and non-precocial (rat) species. J Neurochem 34:17-25

30. Ibayashi S, Fujishima M, Sadoshima S, Yoshida F, Shiokawa O, Ogata J Omae T 1986 Cerebral blood flow and tissue metabolism in experimental cerebral ischemia of spontaneously hypertensive rats with hyper-, normo-, and hypoglycemia. Stroke 17:261-266

31. Zasslow MA, Pearl RG, Shuer LM, Steinberg GK, Lieberson RE, Larson $\mathbf{J}$ CP 1989 Hyperglycemia decreases acute neuronal ischemic changes after middle cerebral artery occlusion in cats. Stroke 20:519-523

32. Blomstrand S, Hrbek A, Karlsson K, Kjellmer I, Lindecrantz K, Olsson T 1984 Does glucose administration affect the cerebral response to fetal asphyxia. Acta Obstet Gynecol Scand 63:345-353

33. Duckrow RB, Bierd DC Brennan RW 1987 Regional cerebral blood flow decreases during chronic and acute hyperglycemia. Stroke 18:52-58

34. Duckrow RB 1988 Regional cerebral blood flow and glucose utilization during hyperinsulinemia. Brain Res 462:363-366

35. Miller CL, Lampard DG, Alexander K, Brown WA 1980 Local cerebral blood flow following transient cerebral ischemia 1. Onset of impaired reperfusion within the first hour following global ischemia. Stroke 11:534-541

36. Rosenberg AA, Parks JK, Murdaugh E, Parker WDJ 1989 Mitochondrial function after asphyxia in newborn lambs. Stroke 20:674-679

37. Bryan RM, Pelligrino DA 1988 Cerebral blood flow during chronic hypoglycemia in the rat. Brain Res 475:397-400 